Baseline

\title{
Perfluorinated compounds in estuarine and coastal areas of north Bohai Sea, China
}

\author{
Tieyu Wang ${ }^{\mathrm{a}}$, Yonglong Lu ${ }^{\mathrm{a}, *}$, Chunli Chen ${ }^{\mathrm{a}}$, Jonathan E. Naile ${ }^{\mathrm{b}}$, Jong Seong Khim ${ }^{\mathrm{c}}$, Jinsoon Park ${ }^{\mathrm{c}}$, \\ Wei Luo ${ }^{a}$, Wentao Jiao ${ }^{a}$, Wenyou Hu ${ }^{a}$, John P. Giesy ${ }^{\text {b,d,e }}$ \\ a State Key Lab of Urban and Regional Ecology, Research Center for Eco-Environmental Sciences, Chinese Academy of Sciences, Beijing 100085, China \\ ${ }^{\mathrm{b}}$ Toxicology Centre and Department of Veterinary Biomedical Sciences, University of Saskatchewan, Saskatoon, SK, Canada S7N 5B3 \\ ${ }^{\mathrm{c}}$ Division of Environmental Science and Ecological Engineering, Korea University, Seoul 136-713, South Korea \\ ${ }^{\mathrm{d}}$ Department of Zoology, College of Science, King Saud University, Riyadh 11451, Saudi Arabia \\ e Department of Zoology and Center for Integrative Toxicology, Michigan State University, East Lansing, 48824 MI, USA
}

\section{A R T I C L E I N F O}

\section{Keywords:}

PFOS

PFOA

Water

Soil

Biota

Risk assessment

\begin{abstract}
A B S T R A C T
Perfluorinated compounds (PFCs) in water, sediment, soil, and biota collected from estuarine and coastal areas of the north Bohai Sea, China, were determined by use of HPLC-MS/MS. Significant concentrations of PFCs were found in water (mean: $18.4 \mathrm{ng} / \mathrm{l}$ ) and biologic samples (fish: $265 \mathrm{ng} / \mathrm{g} \mathrm{dw}$ ), while concentrations of PFCs in soils and sediments were less. The predominately detected compound was perfluorooctanesulfonate (PFOS), with a maximum concentration of $30.9 \mathrm{ng} / \mathrm{l}$ in water and $791 \mathrm{ng} / \mathrm{g} \mathrm{dw}$ in fish. Concentrations of PFCs were significantly greater in the Liaohe River system than other locations, which suggests point sources in this urbanized and industrialized region. PFOS concentrations in water and biota were both less than the reported threshold concentrations. Detection of PFCs at relatively great concentrations in various environmental matrices from this region suggested that further studies characterizing concentrations of PFCs, their sources and potential risk to both humans and wildlife are needed.
\end{abstract}

(c) 2011 Elsevier Ltd. All rights reserved.
Perfluorinated compounds (PFCs) have been manufactured since the 1950s, for their unique properties such as high surface activity, thermal and acid resistance, and water and oil repellency (Giesy and Kannan, 2001, 2002). PFCs have been used in a variety of applications such as surfactants and surface protectors in carpets, leather, paper, food containers, fabric, and upholstery and as performance chemicals in products such as fire-fighting foams, floor polishes, and shampoos (Kissa, 2001). Widespread application followed by environmental persistence and bioaccumulation of terminal degradation products of PFCs has resulted in the global occurrence of these substances in air (Barber et al., 2007; Dreyer and Ebinghaus, 2009; Kim and Kannan, 2007), aquatic systems (Fujii et al., 2007; Rayne and Forest, 2009), as well as wildlife species inhabiting not only locations in close proximity to pollution sources, but also in remote areas (Houde et al., 2006; Fatihah et al., 2009).

Among the PFCs, perfluorooctanesulfonate (PFOS) and perfluorooctanoic acid (PFOA) are regarded as the terminal degradation products, and are the chemicals that are most frequently detected in the environmental and biologic samples, and often occur at the greatest concentrations. PFOS was recently listed as a "persistent organic pollutant", under the Stockholm Convention, but many exemptions were made which allow for continued production and use of some PFCs, especially in China (Wang et al., 2009). In

\footnotetext{
* Corresponding author. Tel.: +86 10 62849466; fax: +86 1062918177

E-mail address: yllu@rcees.ac.cn (Y. Lu).
}

addition, there are a number of other PFCs used commercially that can occur in the environment, including perfluorooctanesulfonamide (PFOSA), perfluorohexanesulfonate (PFHxS), perfluorobutanesulfonate (PFBS), and perfluorononanoic acid (PFNA) (Giesy and Kannan, 2002; Giesy et al., 2010).

Rapid industrial development in China during the past few decades has transformed China into one of the world's largest economies, especially in the Bohai Sea region; a semi enclosed coastal water body on the northeast coast of China. The Bohai Sea, with its nearby coastal areas and rivers/estuaries, is a major commercial artery and has been a region of significant urbanization and industrialization (Liu et al., 2006). Its proximity to Beijing, the capital of China, makes it one of the busiest seaways in the world. The Yellow, Liaohe, Haihe, Luanhe, and Daling Rivers are major freshwater sources discharging directly into the Bohai Sea. Rapid economic development has brought, and continues to bring about increasing amounts of municipal, industrial and agricultural wastes into the water body. The environmental quality in the estuarine and nearby coastal areas has been adversely affected by intense industrial and urban activities, and the Bohai Sea region is currently one of the most polluted areas in China (Hu et al., 2010; Luo et al., 2010; Naile et al., 2010; Wang et al., 2005).

Recently, concentrations of PFCs in water, sediment, and biota in China have been reported (Chen et al., 2009; Ju et al., 2008; Mak et al., 2009; Pan et al., 2010; So et al., 2007; Zhang et al., 2010). However, previous surveys have been limited in their scales 
and matrices, and relatively few studied sources, distribution, and fate among the multiple matrices including: water, sediment, soil, and biota. The present study was one part of a series studies on Bohai Sea and Yellow Sea pollution, conducted as a systematic investigation to trace toxic substances in various environmental media from marine environment and adjacent riverine and estuarine areas of the Yellow Sea including the Bohai Sea of China and the West Sea of Korea. The objectives of the present study were to determine the concentrations, distribution, and fate of PFCs in environmental matrices to identify the sources, and thus provide information for future management and remediation efforts in the Bohai Sea.

This study focused on the coastal and riverine and estuarine areas of northern Bohai Sea, in north-eastern China, including the following eight cities: Tangshan (TS), Qinhuangdao (QH), Huludao (HL), Jinzhou (JZ), Panjin (PJ), Yinkou (YK), Dalian (DL), and Dandong (DD). 36 water, 31 soil, 35 sediment and 42 biologic samples including fishes, crabs, shrimps, clams, frogs, snails and loaches were collected from 16 estuarine and coastal areas along north Bohai Sea during May of 2008 (Fig. 1). Throughout the survey, a global positioning system (GPS) was used to map the position of each sampling site.

One liter of surface water was collected by dipping a clean, methanol rinsed $1 \mathrm{~L}$ polypropylene (PP) bottle just under the surface of the water. Residual chlorine in each water sample was reduced by adding $200 \mu \mathrm{l}$ of $200 \mathrm{mg} / \mathrm{ml}$ of a sodium thiosulfate solution using a disposable PP syringe. Surface (top 1-10 cm) soil and sediment samples were collected using a clean methanol rinsed stainless steel trowel. Representative samples were prepared by mixing five sub-samples from the area of about $5 \mathrm{~m}^{2}$. Samples were transferred and stored in clean PP bags. Biologic samples were collected by hand in coastal tidal pools and along the shores of inland water bodies, and were transferred and stored in clean PP bags. Sample duplicates and field blanks were collected daily, and were analyzed along with laboratory and procedural blanks. All samples were stored on ice for transport to the laboratory and frozen at $-20^{\circ} \mathrm{C}$ until analyses.
Water samples were extracted using Oasis HLB solid phase extraction cartridges (SPE) $\left(0.2 \mathrm{~g}, 6 \mathrm{~cm}^{3}\right)$ (Waters Corp., Milford, MA) as previously reported (Naile et al., 2010; So et al., 2004). Cartridges were preconditioned by eluting with $10 \mathrm{ml}$ of $100 \%$ methanol followed by $10 \mathrm{ml}$ of nano-pure water at a rate of 2 drops a second. $500 \mathrm{ml}$ of water was spiked with $500 \mu \mathrm{l} \mathrm{of} 5 \mathrm{ng} / \mathrm{ml}$ of the internal standard (isotopically labeled PFOS and PFOA, PFOS $\left[{ }^{18} \mathrm{O}_{2}\right]$ and PFOA $\left.\left[1,2,3,4{ }^{13} \mathrm{C}\right]\right)$ and then loaded onto the cartridge, at a rate of 1 drop a second. Cartridges were then washed with $5 \mathrm{ml}$ of $40 \%$ methanol in water and allowed to run dry. Eluents were discarded. Target compounds were eluted with $10 \mathrm{ml}$ of methanol at a rate of 1 drop a second and collected in a $15 \mathrm{ml}$ PP centrifuge tube. The eluate was then reduced to $1 \mathrm{ml}$ under a gentle stream of nitrogen gas, and filtered using a disposable PP syringe, fitted with a disposable nylon membrane Millex filter unit (pore diameter $0.2 \mu \mathrm{m}$, Whatman, Maidstone, United Kingdom). Samples were stored and analyzed in PP auto-sampler vials fitted with PP septa (Canadian Life Science, Peterborough, ON, Canada).

Soil and sediment samples were extracted using a method similar to that described by Higgins et al. (2005) with some modifications. In brief, soils and sediments were freeze-dried and then homogenized with a mortar and pestle and passed through a $2.0 \mathrm{~mm}$ sieve to remove pebbles and debris. Approximately $1.0 \mathrm{~g}$ samples were transferred to a clean $50 \mathrm{ml}$ PP centrifuge tube, and spiked with $500 \mu \mathrm{l}$ of a $5 \mathrm{ng} / \mathrm{ml}$ internal standard, to which $10 \mathrm{ml}$ of a $1 \%$ acetic acid solution was added. Each tube was then vortexed, and placed in a heated sonication bath for $15 \mathrm{~min}$ at $60{ }^{\circ} \mathrm{C}$. After sonication the tubes were centrifuged at $3000 \mathrm{rpm}$ for $3 \mathrm{~min}$ and the acetic acid solution was decanted into a new clean $50 \mathrm{ml}$ PP tube. An aliquant of $2.5 \mathrm{ml}$ of a 90:10 (v/v) methanol and $1 \%$ acetic acid mixture was then added to the original vial and the vial was again vortex mixed and sonicated for $15 \mathrm{~min}$, before being centrifuged and decanted into the second tube. This process was repeated once more, and a final $10 \mathrm{ml}$ acetic acid wash was preformed. All extracts were combined in the second tube before being passed through the SPE cartridge in a similar fashion as described above in the water extraction procedure.

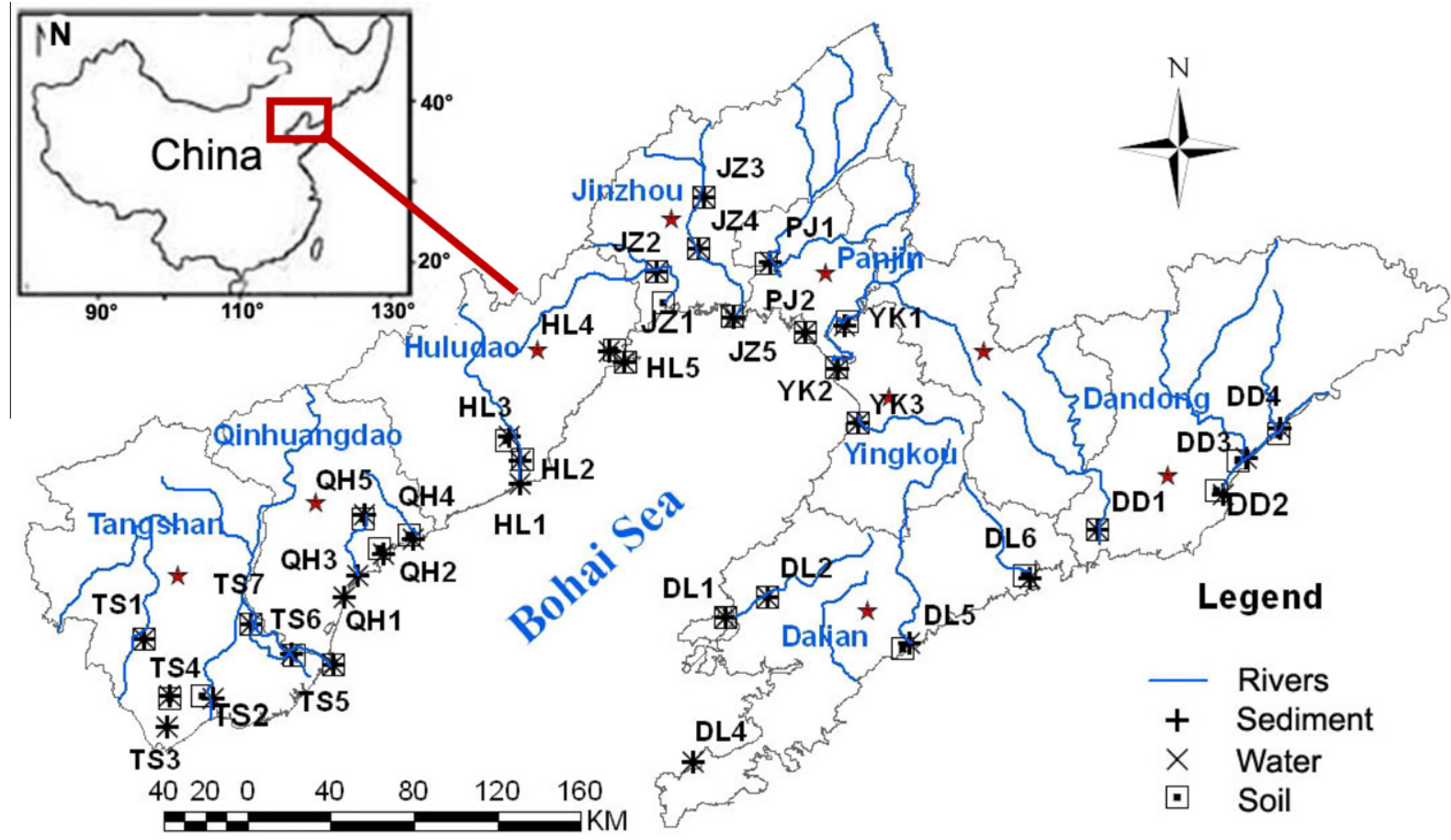

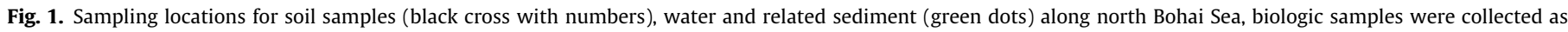
well. (For interpretation of the references to color in this figure legend, the reader is referred to the web version of this article.). 
Biologic samples were extracted using an alkaline digestion SPE method (So et al., 2006) with minor changes. Each sample was thawed and filleted (skin-on), and composite samples from each sampling location were made by combining fillets of the same species. Then the muscle tissues were freeze-dried, ground, then wrapped in aluminum foil and stored at $-20^{\circ} \mathrm{C}$ until chemical analysis. Approximately $1 \mathrm{~g}$ of homogenized tissue sample (dry powder) was transferred to a $50 \mathrm{ml}$ PP centrifuge tube and spiked with $500 \mu \mathrm{l}$ of $5 \mathrm{ng} / \mathrm{ml}$ internal standard, and $30 \mathrm{ml}$ of $0.01 \mathrm{~N} \mathrm{KOH} /$ methanol was added to the tube. The mixture was then shaken at $250 \mathrm{rpm}$ for $16 \mathrm{~h}$ at room temperature. After digestion $5 \mathrm{ml}$ of the resulting tissue solution was added to a $1 \mathrm{~L}$ PP bottle containing $100 \mathrm{ml}$ of nano-pure water and shaken thoroughly. This tissuewater mixture was then extracted using SPE cartridges as previously stated for water extraction procedure.

The internal standard consisted of PFOA $\left[1,2,3,4{ }^{13} \mathrm{C}\right](>98 \%$, Wellington Laboratories, Guelph, ON, Canada) and PFOS $\left[{ }^{18} \mathrm{O}_{2}\right]$ (RTI International, USA). The external standard used for all matrix spikes was a mixture of 12 different PFCs (> 98\%, Wellington Laboratories) including PFBS, PFHxS, PFOS, perfluorodecane sulfonate (PFDS), perfluorobutyric acid (PFBA), perfluorohexanoic acid (PFHxA), perfluoroheptanoic acid (PFHpA), PFOA, PFNA, perfluorodecanoic acid (PFDA), perfluoroundecanoic acid (PFUnA), and perfluorododecanoic acid (PFDoA), and each at a concentration of $6.0 \mathrm{ng} / \mathrm{ml}$ was used as an external standard. HPLC grade methanol and ammonium acetate were purchased from J.T. Baker (Phillipsburg, NJ, USA). Analytical grade sodium thiosulfate was purchased from EMD Chemicals (Gibbstown, NJ, USA). Nano-pure water was obtained from a MilliQ Gradient A-10 (Millipore, Bedford, MA, USA).

A HP 1200 high performance liquid chromatography system (HPLC) by Agilent Technologies was used for separation of all target analytes. The HPLC was fitted with a Thermo Scientific Betasil C18 $(100 \times 2.1 \mathrm{~mm}, 5 \mu \mathrm{m}$ particle size $)$ analytical column, and a suitable guard column was used to prevent instrument background contamination. An aliquant of $2 \mathrm{mM}$ ammonium acetate as an ionization aid and methanol were used as mobile phases. Gradient conditions were used at $300 \mathrm{ml} / \mathrm{min}$ flow rate and $10 \mu \mathrm{l}$ of the sample was injected, starting with $60 \%$ A ( $2 \mathrm{mM}$ ammonium acetate) and $40 \% \mathrm{~B}$ (100\% methanol). Initial conditions were held for $2 \mathrm{~min}$ and then ramped to $20 \% \mathrm{~A}$ at $18 \mathrm{~min}$, held till $20 \mathrm{~min}$, decreased to $0 \%$ A at $21 \mathrm{~min}$, increased to $100 \%$ A at $22 \mathrm{~min}$, held until $22.5 \mathrm{~min}$, returned to initial condition at $23 \mathrm{~min}$, and finally held constant until $26 \mathrm{~min}$. The temperature of the column oven was kept constant at $35^{\circ} \mathrm{C}$.
Mass spectra were collected using an Applied Biosystems SCIEX 3000 (Foster City, CA) tandem mass spectrometer, fitted with an electrospray ionization source, operated in negative ionization mode. Chromatograms were recorded using a multiple reaction monitoring mode (MRM) with a dwell time of $40 \mathrm{~ms}$. The following instrument parameters were used: desolvation temperature $\left(450^{\circ} \mathrm{C}\right)$, desolvation (curtain) gas 6.0 arbitrary units (AU); nebulizer gas flow $5 \mathrm{AU}$; ion spray voltage $-3500 \mathrm{~V}$; and collision gas $12 \mathrm{AU}$. The optimal settings for collision energies and declustering potential were determined for each analyte's transitions. Quantification using these transitions was performed using Analyst 1.4 .1 software provided by SCIEX (Applied Bioscience, Foster City, CA).

In order to insure the accuracy of the sampling, extraction, and analytical procedures, field blanks were obtained with each set of water samples analyzed. Procedural blanks and recoveries were determined for each set of extractions. Quantification was performed using the internal standard method based on ${ }^{18} \mathrm{O}_{2}$-PFOS and ${ }^{13} \mathrm{C}_{4}$-PFOA as the surrogate. To reduce instrument background contamination coming from the HPLC or solvents, a ZORBEX (Thermo Scientific, $50 \times 2.1 \mathrm{~mm}, 5 \mu \mathrm{m}$ particle size) column was inserted directly before the injection-valve, as adapted from Benskin et al. (2007). All field and laboratory blanks were below the limit of quantification (LOQ), where the LOQ was defined as 5 times the background noise. The use of Teflon coated lab-ware was avoided during all steps of sample preparation and analysis to minimize contamination of the samples. The ions monitored, method detection limit (MDL), and matrix spike recoveries for all of the chemicals of interest are summarized (Table 1).

Detectable concentrations of waterborne PFCs, were observed at most locations in estuarine and coastal areas of north Bohai Sea (Fig. 2, Table 2). All of the PFCs, except for PFBS, PFHxS, PFDS and PFDoA, were detected in water samples and particularly PFOS, PFOA, PFBA, PFHxA, and PFHpA were detected in more than half of water samples analyzed. Among 12 different compounds were investigated, PFOS and PFOA were consistently found at the greatest concentrations (Fig. 2), except for limited locations in Dalian area (DL locations). Thus the discussion will concentrate on PFOS and PFOA. Almost all of the water samples contained detectable concentrations of PFOS and PFOA. Concentrations of PFOS and PFOA ranged from < LOQ to $30.9 \mathrm{ng} / \mathrm{l}$ with a mean of $6.98 \mathrm{ng} / \mathrm{l}$ and from< LOQ to $81.7 \mathrm{ng} / \mathrm{l}$ with a mean of $14.1 \mathrm{ng} / \mathrm{l}$, respectively. They were found to be the predominant waterborne PFCs accounting for about $62 \%$ relative to total.

Table 1

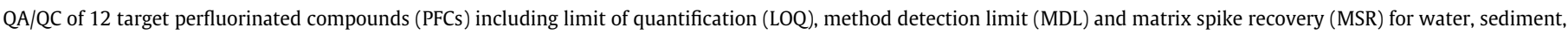
soil, and biologic samples.

\begin{tabular}{|c|c|c|c|c|c|c|c|c|c|c|}
\hline \multirow[t]{2}{*}{ Compounds } & \multirow[t]{2}{*}{ Acronym } & \multicolumn{3}{|l|}{ LOQ } & \multicolumn{3}{|l|}{ MDL } & \multicolumn{3}{|l|}{ MSR } \\
\hline & & $\begin{array}{l}\mathrm{W}^{\mathrm{a}} \\
(\mathrm{ng} / \mathrm{l})\end{array}$ & $\begin{array}{l}S^{b} \\
(n g / g d w)\end{array}$ & $\mathrm{B}^{\mathrm{c}}$ & $\begin{array}{l}\text { W } \\
(\mathrm{ng} / \mathrm{l})\end{array}$ & $\begin{array}{l}\text { S } \\
(\mathrm{ng} / \mathrm{g} \mathrm{dw})\end{array}$ & B & $\begin{array}{l}\mathrm{W} \\
(\%)\end{array}$ & $\mathrm{S}$ & B \\
\hline Perfluorobutanesulfonate & PFBS & 0.5 & 1 & 1 & 1 & 1 & 1 & 94 & 32 & 97 \\
\hline Perfluorohexanesulfonate & PFHxS & 0.1 & 0.5 & 1 & 0.2 & 0.5 & 1 & 136 & 134 & 113 \\
\hline Perfluorooctanesulfonate & PFOS & 0.1 & 0.5 & 0.1 & 0.2 & 0.5 & 0.1 & 101 & 95 & 85 \\
\hline Perfluorodecanesulfonate & PFDS & 0.1 & 0.5 & 0.1 & 0.2 & 0.5 & 0.1 & 101 & 43 & 68 \\
\hline Perfluorobutanoic acid & PFBA & 1 & 1 & 1 & 2 & 1 & 1 & 120 & $\mathrm{IS}^{\mathrm{d}}$ & 10 \\
\hline Perfluorohexanoic acid & PFHxA & 0.5 & 0.1 & 0.1 & 1 & 0.1 & 1 & 85 & 79 & 73 \\
\hline Perfluoroheptanoic acid & PFHpA & 0.5 & 0.1 & 0.1 & 1 & 0.1 & 0.1 & 103 & 123 & 104 \\
\hline Perfluorooctanoic acid & PFOA & 0.5 & 0.5 & 0.5 & 1 & 0.5 & 0.5 & 88 & 89 & 85 \\
\hline Perfluorononanoic acid & PFNA & 1 & 1 & 1 & 2 & 1 & 1 & 132 & 135 & 123 \\
\hline Perfluorodecanoic acid & PFDA & 0.1 & 0.1 & 0.1 & 0.2 & 0.1 & 0.1 & 93 & 106 & 71 \\
\hline Perfluoroundecanoic acid & PFUnA & 1 & 0.5 & 1 & 2 & 0.5 & 1 & 112 & 53 & 86 \\
\hline Perfluorododecanoic acid & PFDoA & 1 & 0.1 & 1 & 2 & 0.1 & 0.5 & 77 & 70 & 47 \\
\hline
\end{tabular}

a W, abbreviation of water.

b $S$, abbreviation of soil and sediment.

c $\mathrm{B}$, abbreviation of biologic samples.

d IS, Insufficient recovery. 
The greatest concentrations of PFCs (121 ng/l) were found at locations JZ5, JZ3 and JZ4 (Fig. 2). These locations contained greater concentrations of all detectable PFCs, except for PFOS. PFOA was the dominant contributor to PFCs in this area, and its concentration in JZ3, JZ4 and JZ5 were $68.1 \mathrm{ng} / \mathrm{l}, 72.2 \mathrm{ng} / \mathrm{l}$, and $81.7 \mathrm{ng} / \mathrm{l}$, respectively. These samples were collected from the Daling River adjacent to the cities of Jinzhou and Huludao, which has been one of the largest chemical industrial areas of China since the 1960s. There are still oil refining plants, chemical plants, and smelting plants in this region. The Daling River is one tributary of the Liaohe River system, which is one of the most contaminated water bodies in China (Zhang et al., 2006). The greatest concentration of PFOS (30.9 ng/l) was observed at location YK1, which is located in the Daliao River, a main tributary of the Liaohe River system adjacent to the city of Yingkou. As a major water-receiving body, the Liaohe River system is influenced by sewage from the surrounding cities, and receives about 2 billion tons of industrial and domestic wastewater annually (Zhang et al., 2009). The watershed encompasses a number of densely industrialized zones with machinery, electronics, metal refining, and petroleum and chemical industries.

Compared to other research findings for China, concentrations of PFCs in waters from estuarine and coastal areas of northern Bohai Sea were greater than those from the Pearl River Delta, where the first study of PFCs in China was conducted, and the Chongqing, Yichang, Dongguan, Wuhan, Nanjing, and Beijing regions (Jin, 2006; So et al., 2007; So et al., 2004; Zhao et al., 2007) (Table 3). Moreover, it has been reported that PFOS and PFOA concentrations around the city of Dalian from coastal areas of the Bohai Sea were less than those found in the present study as well, ranging from nd to $2.25 \mathrm{ng} / \mathrm{l}$ and from 0.170 to $37.6 \mathrm{ng} / \mathrm{l}$, respectively (Ju et al., 2008).

In general, PFOS and PFOA concentrations in waters from estuarine and coastal areas of northern Bohai Sea were consistent with
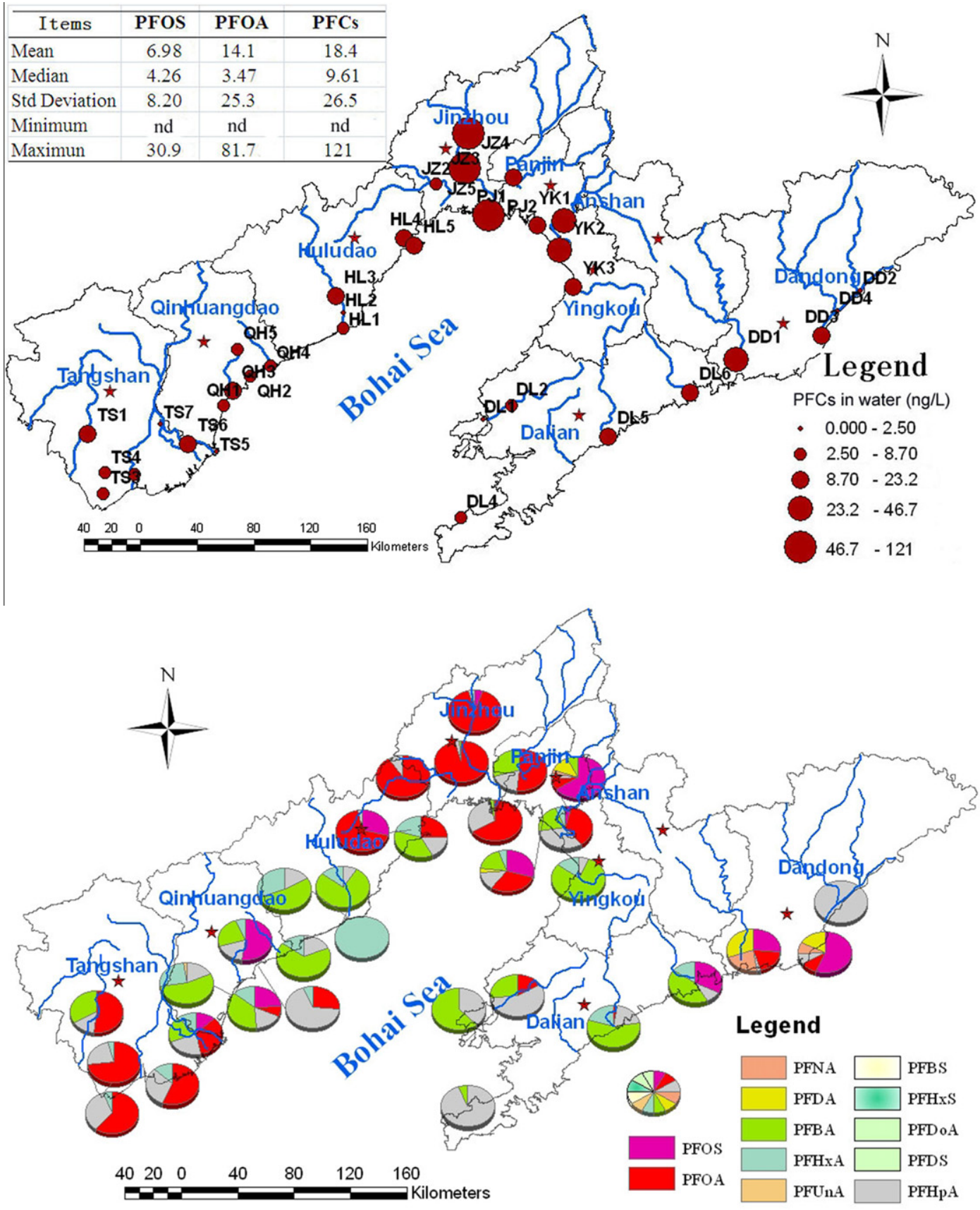

Fig. 2. Spatial distributions and relative contributions of individual PFCs to total (\%) in water from north Bohai Sea. 
Table 2

Overview of PFCs analysis results for water, sediment, soil, and biologic samples collected from north Bohai Sea.

\begin{tabular}{lllll}
\hline Compounds & Water & Sediment & Soil & Biologic \\
\hline Sampling location $(n)$ & 36 & 35 & 31 & 25 \\
Samples analyzed $(n)$ & 36 & 35 & 31 & 42 \\
Samples detected & $n(\%)$ & & & \\
PFBS & $0(0)$ & $0(0)$ & $0(0)$ & $3(7)$ \\
PFHxS & $0(0)$ & $0(0)$ & $0(0)$ & $0(0)$ \\
PFOS & $12(33)$ & $3(9)$ & $2(6)$ & $20(48)$ \\
PFDS & $0(0)$ & $0(0)$ & $0(0)$ & $2(5)$ \\
PFBA & $23(64)$ & $0(0)$ & $0(0)$ & $16(38)$ \\
PFHxA & $22(61)$ & $4(11)$ & $0(0)$ & $9(21)$ \\
PFHpA & $32(89)$ & $1(3)$ & $0(0)$ & $1(2)$ \\
PFOA & $21(58)$ & $3(9)$ & $9(26)$ & $11(26)$ \\
PFNA & $3(8)$ & $13(37)$ & $15(43)$ & $1(2)$ \\
PFDA & $5(14)$ & $2(6)$ & $1(3)$ & $33(78)$ \\
PFUnA & $3(8)$ & $16(46)$ & $11(31)$ & $7(17)$ \\
PFDoA & $0(0)$ & $0(0)$ & $0(0)$ & $0(0)$ \\
Average detected & $10(28)$ & $4(11)$ & $3(10)$ & $9(21)$ \\
\hline
\end{tabular}

the results of previous studies (Table 3 ). Concentrations observed in the present study were greater than those found in most rivers of Japan and much greater than those found offshore of Japan and oceanic samples including the Western Pacific Ocean, Central to Eastern Pacific Ocean and North Atlantic Ocean (Yamashita et al., 2005). Concentrations of PFOS and PFOA were either comparable to or less than those detected in coastal waters of South Korea (Naile et al., 2010; Rostkowski et al., 2006), Yodo River Basin, Japan (Lein et al., 2008) and various river and coastal waters in Brazil (Quinete et al., 2009). Concentrations of PFOS and PFOA measured in this study were similar to those reported for Tokyo Bay, Japan (Sakurai et al., 2010; Yamashita et al., 2004). In the present study, the maximal concentrations of PFOS (30.9 ng/l) and PFOA (81.7 ng/ 1) were measured in Liaodong Bay, which were less than the greatest concentrations of PFOS (123 ng/l) and PFOA (2600 ng/l) measured in the Yodo River Basin, which is one of the most polluted rivers in Japan.
Although PFOS and PFOA were the dominant PFCs found in water samples in the present study, PFBA, PFHxA and PFHpA were detected in approximately $70 \%$ of the samples analyzed at concentrations greater than the LOQ, but the concentrations of these PFCs were less than those of PFOS and PFOA. Concentrations of PFBA, PFHxA and PFHpA ranged from < LOQ to $74.1 \mathrm{ng} / \mathrm{l},<\mathrm{LOQ}$ to $2.32 \mathrm{ng} / \mathrm{l}$, and < LOQ to $34.5 \mathrm{ng} / \mathrm{l}$, with a means of $3.44 \mathrm{ng} / \mathrm{l}$, $1.19 \mathrm{ng} / \mathrm{l}$, and $2.85 \mathrm{ng} / \mathrm{l}$, respectively. This indicates that other PFCs, in addition to PFOS and PFOA, should be considered in future monitoring and risk assessment. However, it should be noted that the reported concentrations of waterborne PFCs were based on a single survey, thus temporal variations could not be addressed at this time. Further studies would be conducted to look at monthly or seasonal variations in PFCs concentrations in these areas.

As sediments are considered to be the ultimate sinks and reservoirs of many contaminants, information about sediment contamination is essential in the assessment of the impact of human activities on aquatic systems. Concentrations of PFCs in sediments from the estuarine and coastal areas of north Bohai Sea were generally less than the corresponding MDLs. Total concentrations of PFCs ranged from < LOQ to $4.31 \mathrm{ng} / \mathrm{g}$ dw with a mean of $0.622 \mathrm{ng} / \mathrm{g}$ dw. PFOS and PFOA were the dominant PFCs with concentrations that ranged from < LOQ to $1.97 \mathrm{ng} / \mathrm{g} \mathrm{dw}$ with a mean of $1.67 \mathrm{ng} / \mathrm{g}$ dw and from < LOQ to $0.542 \mathrm{ng} / \mathrm{g} \mathrm{dw}$ with a mean of $0.298 \mathrm{ng} / \mathrm{g} \mathrm{dw}$, respectively (Fig. 3). Concentrations of the other ten target analytes were less than their respective LOQs at most of the sampling locations except for PFNA and PFUnA. Concentrations of PFOS were greater than those of PFOA at all locations where they were detected.

The greatest concentrations of PFOA $(0.542 \mathrm{ng} / \mathrm{g} \mathrm{dw})$ and second greatest concentration of PFOS $(1.55 \mathrm{ng} / \mathrm{g} \mathrm{dw})$ were observed in sediments from $\mathrm{QH} 2$, and considerably elevated concentration of PFOS (1.48 ng/g dw) was found in the same vicinity (QH3). These sites, located at the mouth of the Tang River Estuary, close to a sewage outfall and industrial discharge, reflected a potential pollution source of PFOS and PFOA from Qinhuangdao City. Furthermore, the greatest concentration of PFOS $(1.97 \mathrm{ng} / \mathrm{g} \mathrm{dw})$

Table 3

Comparison of PFOS and PFOA concentrations (ng/l) in water with other studies in these adjacent areas.

\begin{tabular}{|c|c|c|c|c|}
\hline Location & & PFOS & PFOA & Reference \\
\hline China & $\begin{array}{l}\text { Estuarine and coastal areas of north Bohai Sea } \\
\text { Coastal area of China } \\
\text { Beijing } \\
\text { Dongguan } \\
\text { Chongqing } \\
\text { Yichang } \\
\text { Wuhan } \\
\text { Nanjing } \\
\text { Shanghai } \\
\text { Pearl river delta } \\
\text { Dalian coast } \\
\text { Hong Kong }\end{array}$ & $\begin{array}{l}\text { nd-30.9 } \\
0.02-9.68 \\
1.75-4.09 \\
0.90-99 \\
\text { nd-0.35 } \\
0.29-0.61 \\
2.3-5.3 \\
0.33-0.38 \\
0.62-14 \\
0.02-12 \\
\text { nd-2.25 } \\
0.09-3.1\end{array}$ & $\begin{array}{l}2.58-81.7 \\
0.24-15.3 \\
5.51-7.85 \\
0.85-4.4 \\
\text { nd-35 } \\
4.1-4.9 \\
2.8-5.6 \\
2.1-2.4 \\
22-260 \\
0.24-16 \\
0.17-37.6 \\
0.73-5.5\end{array}$ & $\begin{array}{l}\text { This study } \\
\text { Yamashita et al., } 2005 \\
\text { Zhao et al., } 2007 \\
\text { So et al., } 2007 \\
\text { So et al., } 2007 \\
\text { So et al., } 2007 \\
\text { Jin et al.,2006 } \\
\text { So et al., } 2007 \\
\text { So et al., } 2007 \\
\text { So et al., } 2004 \\
\text { Ju et al., } 2008 \\
\text { So et al., } 2004\end{array}$ \\
\hline Japan & $\begin{array}{l}\text { Tokyo Bay } \\
\text { Tokyo Bay } \\
\text { Survey of Japan } \\
\text { Yodo river basin } \\
\text { Kyoto } \\
\text { Offshore of Japan }\end{array}$ & $\begin{array}{l}12.7-25.4 \\
0.78-17 \\
0.89-5.73 \\
0.4-123 \\
7.9-110 \\
0.04-0.07\end{array}$ & $\begin{array}{l}154-192 \\
2.7-63 \\
0.97-21.5 \\
4.2-2600 \\
5.12-10 \\
0.14-1.06\end{array}$ & $\begin{array}{l}\text { Yamashita et al., } 2004 \\
\text { Sakurai et al., } 2010 \\
\text { Saito et al., } 2003 \\
\text { Lein et al., } 2008 \\
\text { Senthilkumar et al., } 2007 \\
\text { Yamashita et al., } 2005\end{array}$ \\
\hline South Korea & $\begin{array}{l}\text { Coastal area of Korea } \\
\text { West and South coasts of Korea } \\
\text { West coasts of Korea } \\
\text { Gyeonggi Bay }\end{array}$ & $\begin{array}{l}0.04-2.53 \\
0.04-730 \\
4.11-450 \\
2.24-651\end{array}$ & $\begin{array}{l}0.24-11.4 \\
0.24-320 \\
2.95-68.6 \\
0.9-62\end{array}$ & $\begin{array}{l}\text { Yamashita et al., } 2005 \\
\text { So et al., } 2004 \\
\text { Naile et al., } 2010 \\
\text { Rostkowski et al., } 2006\end{array}$ \\
\hline Ocean & $\begin{array}{l}\text { Western Pacific ocean } \\
\text { Central to Eastern Pacific ocean } \\
\text { North Atlantic ocean }\end{array}$ & $\begin{array}{l}0.054-0.078 \\
0.001-0.020 \\
0.009-0.036\end{array}$ & $\begin{array}{l}0.136-0.142 \\
0.015-0.062 \\
0.160-0.338\end{array}$ & $\begin{array}{l}\text { Yamashita et al., } 2005 \\
\text { Yamashita et al., } 2005 \\
\text { Yamashita et al., } 2005\end{array}$ \\
\hline
\end{tabular}

nd = not detectable, means concentration less than corresponding LOQs. 


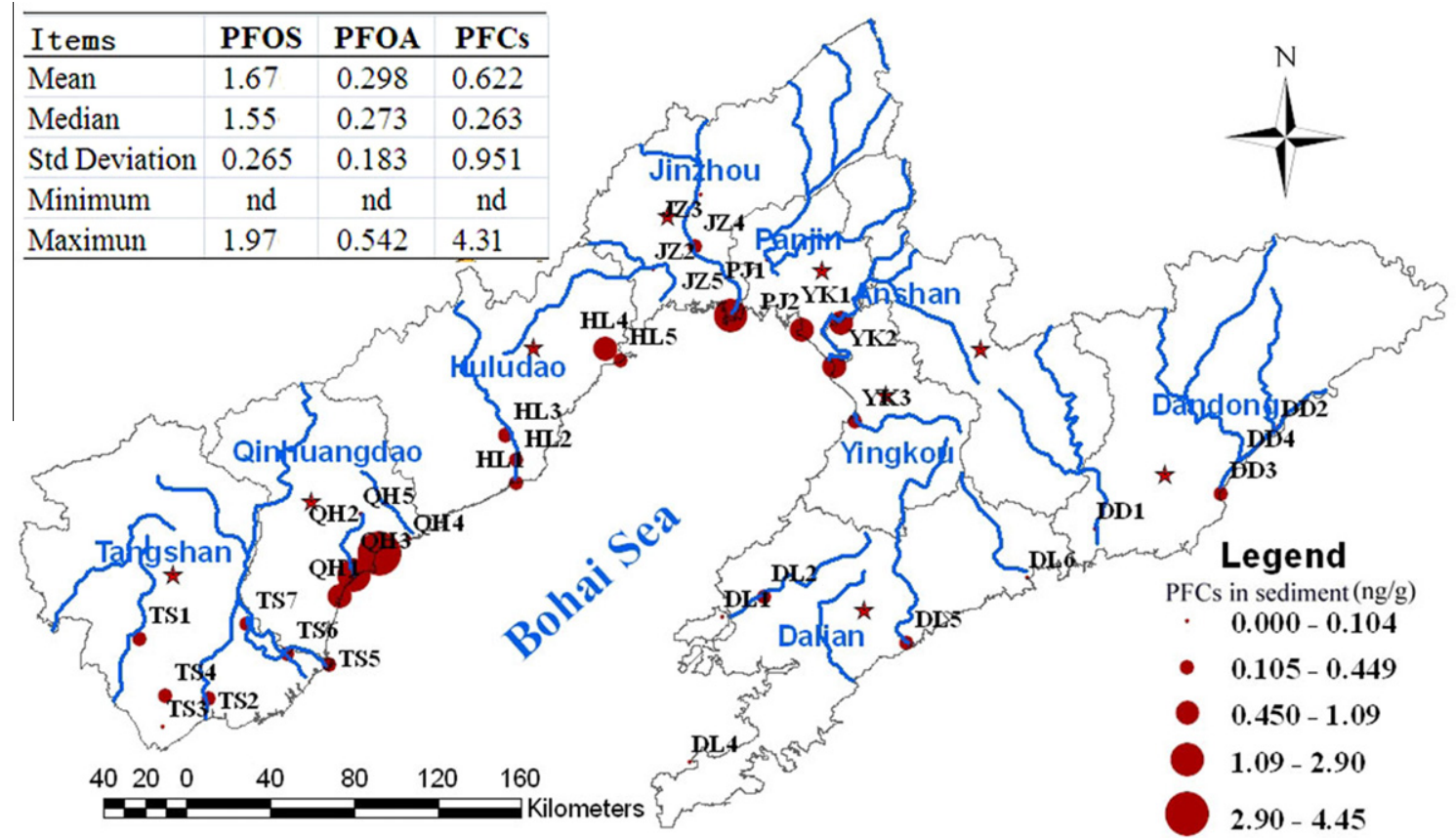

Fig. 3. Spatial distributions of PFCs in sediments from north Bohai Sea.

and relatively great concentration of PFOA $(0.305 \mathrm{ng} / \mathrm{g} \mathrm{dw})$ were found in riverine sediment from the Jinzhou area (JZ4). This was also an area where some of the greatest PFCs concentrations were observed in water.

Compared to previous studies, concentrations of PFOS in sediments from the estuarine and coastal areas of the northern Bohai Sea were similar to those from the Zhujiang River, China $(<$ LOQ - $3.10 \mathrm{ng} / \mathrm{g} \mathrm{dw}$ ) (Bao et al., 2010) and four rivers by San Francisco Bay, USA (<LOQ - $1.30 \mathrm{ng} / \mathrm{g} \mathrm{dw}$ ) (Higgins et al., 2005), but less than those from the Kyoto River, Japan (<LOQ - $11.0 \mathrm{ng} / \mathrm{g} \mathrm{dw})$ (Senthilkumar et al., 2007). The maximum concentration of PFOS in sediments $(1.97 \mathrm{ng} / \mathrm{g} \mathrm{dw})$ in the present study was greater than those reported from the Daliao River system, China $(<\mathrm{LOQ}-$ $0.37 \mathrm{ng} / \mathrm{g} \mathrm{dw}$ ) (Bao et al., 2009), the Huangpu River, China (< LOQ - $0.46 \mathrm{ng} / \mathrm{g} \mathrm{dw}$ ) (Bao et al., 2010), the tidal flat areas of Ariake Sea, Japan (0.09-0.14 ng/g dw) (Nakata et al., 2006), and the Roter Main River, Germany (0.07-0.31 ng/g dw) (Becker et al., 2008).

Concentrations of PFOA in sediments of this watershed were greater than those of the Daliao River system, China (nd $0.17 \mathrm{ng} / \mathrm{g} \mathrm{dw}$ ) (Bao et al., 2009) and the Roter Main River, Germany (0.02-0.07 ng/g dw) (Becker et al., 2008), comparable to those from the Huangpu River $(0.20-0.64 \mathrm{ng} / \mathrm{g} \mathrm{dw})$ and the Zhujiang River (0.09-0.29 ng/g dw), China (Bao et al., 2010), and San Francisco Bay, USA (0.16-0.23 ng/g dw) (Higgins et al., 2005), whereas they were less than those of the Kyoto River $(<\mathrm{LOQ}-3.9 \mathrm{ng} / \mathrm{g} \mathrm{dw}$ ) (Senthilkumar et al., 2007) and the Ariake Sea, Japan (0.84$1.1 \mathrm{ng} / \mathrm{g} \mathrm{dw}$ ) (Nakata et al., 2006). Overall, concentrations of PFOA observed in sediments during the present study varied widely, which indicates multiple sources across the estuarine and coastal areas of the northern Bohai Sea.

Concentrations of PFCs in wildlife are given in Table 4. PFOS was greater than the LOQ in $67 \%$ of all biologic samples taken from the estuarine and coastal areas of the northern Bohai Sea and PFOS was found to be the most frequently detected PFC (Table 2). Concentrations of PFOS in fish, loach, shrimp, clam, crab, frog, and snail were $262 \mathrm{ng} / \mathrm{g} \mathrm{dw}, 44.5 \mathrm{ng} / \mathrm{g} \mathrm{dw}, 14.0 \mathrm{ng} / \mathrm{g} \mathrm{dw}, 5.72 \mathrm{ng} / \mathrm{g} \mathrm{dw}, 2.64 \mathrm{ng} / \mathrm{g}$ $\mathrm{dw}$, nd, and $<\mathrm{LOQ}$ respectively. This indicates the greatest accumulation in organisms at the top of the food web, such as fish. Concentrations of PFOA in biota were less than those of PFOS, with
Table 4

Concentrations (ng/g dw) of PFCs in biologic samples from north Bohai Sea.

\begin{tabular}{|c|c|c|c|c|c|c|c|}
\hline $\begin{array}{l}\text { Compounds } \\
\text { No. of samples }\end{array}$ & $\begin{array}{l}\text { Fish } \\
13\end{array}$ & $\begin{array}{l}\text { Crab } \\
14\end{array}$ & $\begin{array}{l}\text { Shrimp } \\
3\end{array}$ & $\begin{array}{l}\text { Clam } \\
6\end{array}$ & $\begin{array}{l}\text { Frog } \\
2\end{array}$ & $\begin{array}{l}\text { Snail } \\
2\end{array}$ & $\begin{array}{l}\text { Loach } \\
2\end{array}$ \\
\hline PFOS & 262 & 2.64 & 14.0 & 5.72 & nd & nd & 44.5 \\
\hline PFOA & nd & 1.45 & 2.26 & nd & nd & nd & 0.790 \\
\hline PFHxA & 0.692 & 0.242 & nd & 1.16 & 2.90 & nd & 1.00 \\
\hline PFDA & 1.18 & 1.21 & 0.918 & 0.705 & 4.01 & nd & 1.25 \\
\hline PFUnA & 0.258 & 0.433 & nd & 1.37 & nd & nd & nd \\
\hline PFBA & 1.37 & 1.66 & nd & 1.11 & 1.07 & nd & nd \\
\hline PFCs & 265 & 7.63 & 17.2 & 10.1 & 7.97 & nd & 47.5 \\
\hline
\end{tabular}

a detection rate of only $26 \%$. Corresponding, the concentrations of PFOA in shrimp, crab, loach, fish, clam, frog, and snail were $2.26 \mathrm{ng} /$ $\mathrm{g} \mathrm{dw}, 1.45 \mathrm{ng} / \mathrm{g} \mathrm{dw}, 0.790 \mathrm{ng} / \mathrm{g} \mathrm{dw}$, nd, nd, nd, and nd, respectively.

Considering that fish and crabs are among the most abundant organisms in this area and were collected from almost all sub-regions of sampling areas, the six most commonly detected PFCs in those organisms were further analyzed (Fig. 4). PFOS was the predominately detected PFC in fish, $(n=25)$ throughout the study area, with quantifiable concentrations ranging from $0.86 \mathrm{ng} / \mathrm{g} \mathrm{dw}$ at TS (Tangshan) to $791 \mathrm{ng} / \mathrm{g} \mathrm{dw}$ at DD (Dandong). Fish collected from DL (Dalian) and YK (Yingkou) contained greater concentrations of PFOS (238 ng/g dw and $573 \mathrm{ng} / \mathrm{g} \mathrm{dw}$ ) as well. PFOS, PFOA and PFDA were detected in most samples of crab, but concentrations were less and there was little variation among concentrations of target PFCs. PFOS concentrations in crabs ranged from < LOQ at YK and QH (Qinhuangdao) to $8.73 \mathrm{ng} / \mathrm{g} \mathrm{dw}$ at TS, and the second greatest concentration $(7.17 \mathrm{ng} / \mathrm{g} \mathrm{dw})$ in crabs was from DD. This concentration was similar to that observed in fish, which indicates possible sources near Dandong City. The greatest concentration of PFOA (3.13 ng/g dw) and PFDA $(0.945 \mathrm{ng} / \mathrm{g} \mathrm{dw})$ were observed in crabs from TS.

Greater concentrations of PFOS in fish were observed in the eastern part of the northern Bohai Sea (Fig. 4), with a mean of $534 \mathrm{ng} / \mathrm{g}$ dw. This concentration was comparable to those observed previously in South Korea, Japan, Brazil, and Germany (Becker 
et al., 2010; Naile et al., 2010; Nakata et al., 2006; Quinete et al., 2009; Taniyasu et al., 2003; Yoo et al., 2009), but generally greater than those previously reported in China, the North American Great Lakes, and Netherlands (Boulanger et al., 2004; Delinsky et al., 2010; Gulkowska et al., 2006; Kwadijk et al., 2010; Shi et al., 2010). These locations have been subjected to anthropogenic influences as a result of rapid urbanization and industrialization. Overall, they seemed to be influenced primarily by domestic sewage and industrial effluent from the nearby areas of highly urbanized and industrialized zones of Yingkou, Dalian and Dandong cities.
PFCs have been reported at greater concentrations in urban areas than in the rural areas, which indicates that in addition to industrial activities urban areas are also the sources of PFCs (Kim and Kannan, 2007; Nakata et al., 2006; Saito et al., 2003; Taniyasu et al., 2003). Releases from various PFCs sources not only contaminate water systems but also contaminate soils. For example, PFOS and PFOA can absorb onto sediment and sludge (Hansen et al., 2002; Higgins et al., 2005; Sinclair and Kannan, 2006), therefore, soils could be another sink for PFCs. Previous studies have reported concentrations of PFCs in water, sediment and biologic samples,
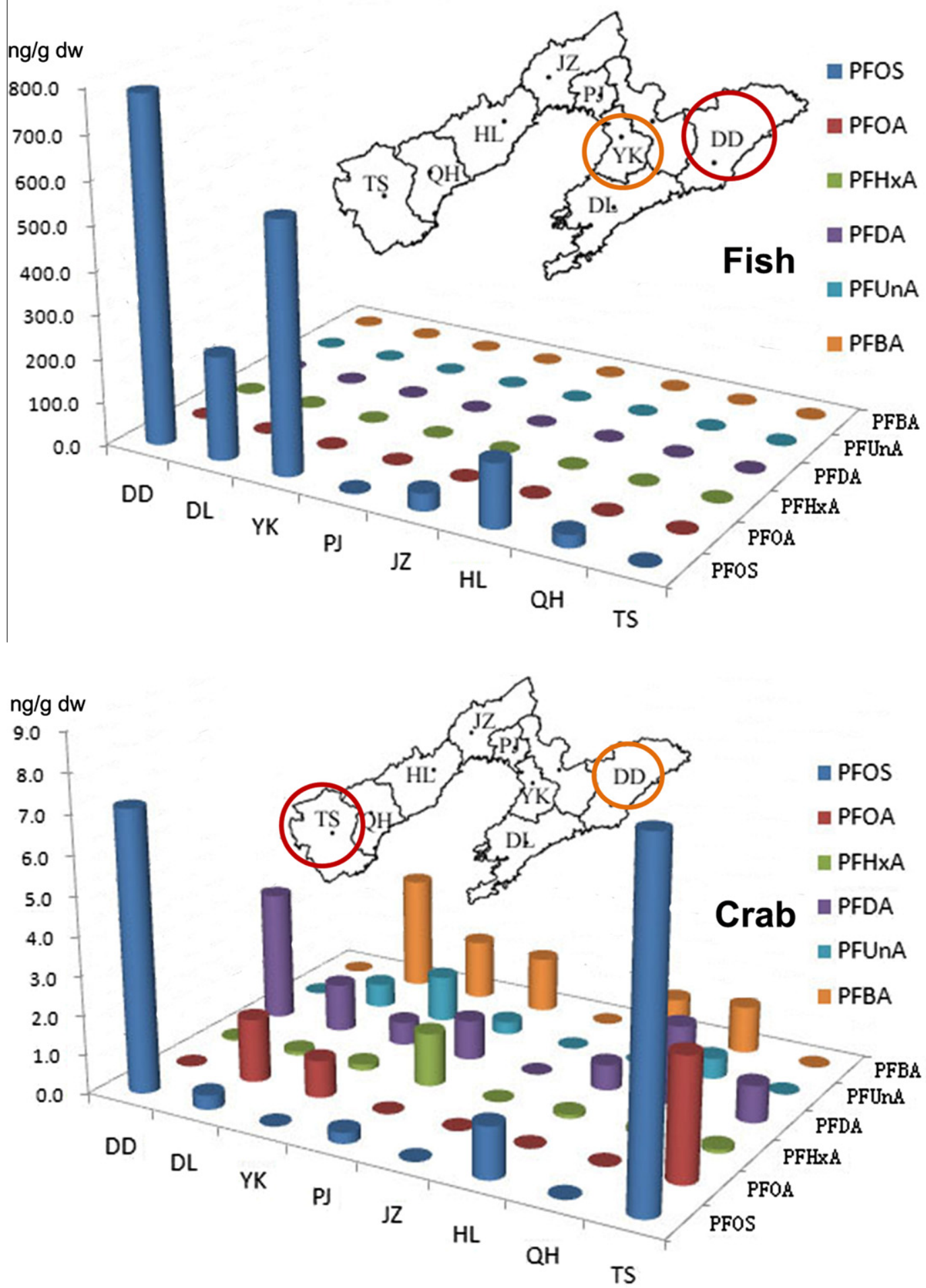

Fig. 4. Spatial distribution and compositional patterns of PFCs detected in fish and crabs from different areas along north Bohai Sea. 
however, few have reported the occurrence, distribution, sources and risks of PFCs in soils (Naile et al., 2010).

Spatial distribution of 12 PFCs in soils was generated by using ArcGis software (ESRI, US), and an interpolation method of Ordinary Kriging was adopted for the interpolation of geographic data (Fig. 5). In the estuarine and coastal areas of northern Bohai Sea, concentrations of PFCs in soils were generally less than the LOQ. Only two sites contained detectable concentrations of PFOS and nine sites contaied PFOA greater than the LOQ. However, PFNA and PFUnA were found at a relatively great rate of occurrence with
$43 \%$ and $31 \%$, respectively (Table 2 ), which was the similar case in the distribution of sedimentary PFCs. Total concentrations of PFCs were in the range of $<$ LOQ $-1.72 \mathrm{ng} / \mathrm{g}$ dw with a mean of $0.579 \mathrm{ng} / \mathrm{g}$ dw. Concentrations of PFOS and PFOA in soils ranged from $<$ LOQ to $0.702 \mathrm{ng} / \mathrm{g} \mathrm{dw}$ with a mean of $0.582 \mathrm{ng} / \mathrm{g} \mathrm{dw}$ and from < LOQ to $0.473 \mathrm{ng} / \mathrm{g} \mathrm{dw}$ with a mean of $0.210 \mathrm{ng} / \mathrm{g} \mathrm{dw}$, respectively (Fig. 5). While concentrations of the other two routinely found PFCs of PFNA and PFUnA were comparable, ranging from $<$ LOQ to $0.701 \mathrm{ng} / \mathrm{g} \mathrm{dw}$ with a mean of $0.281 \mathrm{ng} / \mathrm{g} \mathrm{dw}$ and from nd to $0.421 \mathrm{ng} / \mathrm{g} \mathrm{dw}$ with a mean of $0.259 \mathrm{ng} / \mathrm{g} \mathrm{dw}$, respectively. There

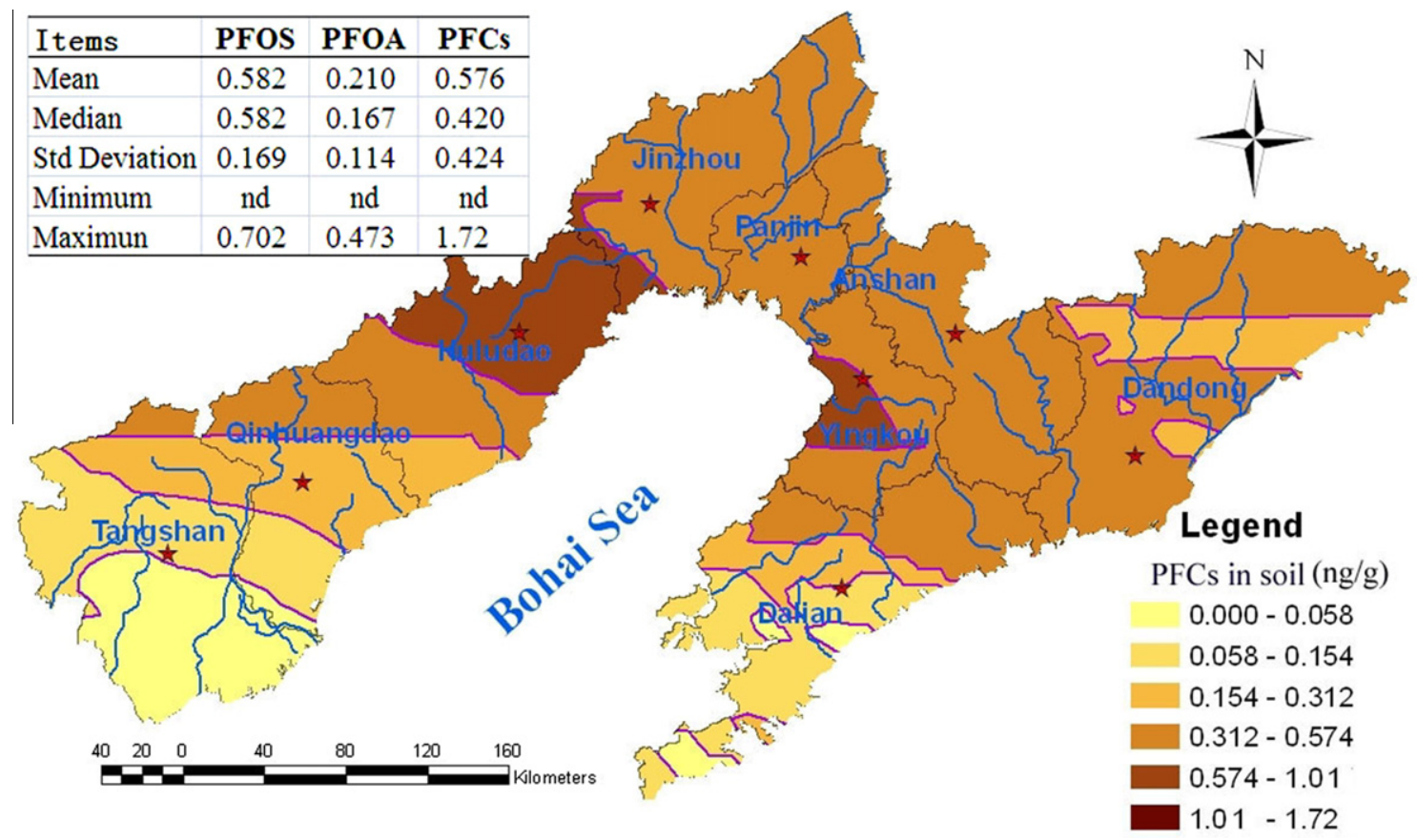

Fig. 5. Spatial distributions of PFCs in soils from north Bohai Sea.

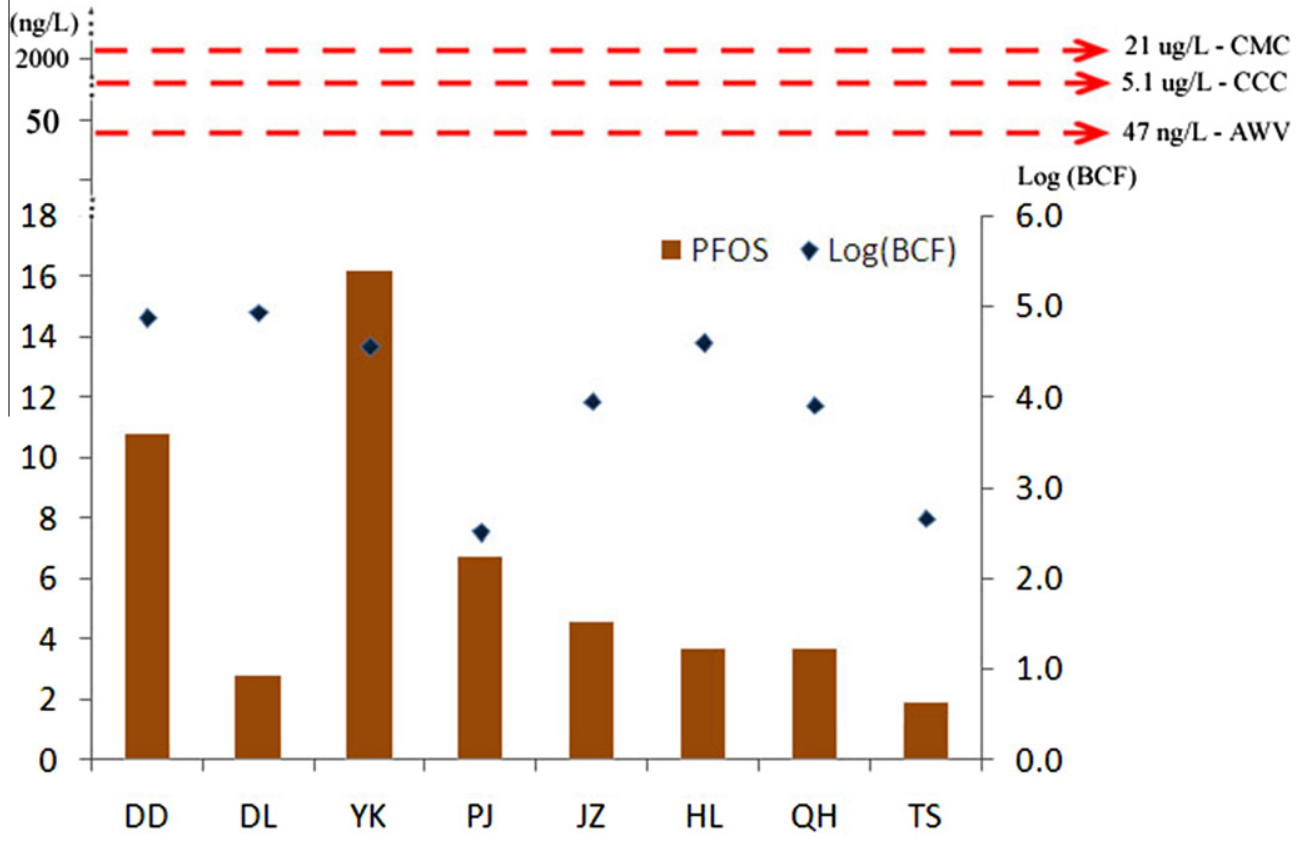

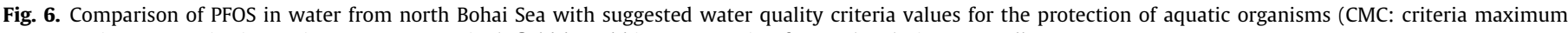
concentration; CCC: criteria continuous concentration), field-based bioconcentration factors (BCF) given as well. 
did not seem to be a significant difference in the amount of PFCs accumulation between soils and sediments, as neither had a PFOS and PFOA concentration greater than $2.0 \mathrm{ng} / \mathrm{g} \mathrm{dw}$, however.

Concentrations of PFCs in soils exhibited a spatial pattern that was different from that in sediments. The greatest concentrations were observed at HL5, which is adjacent to the city of Huludao. The greatest concentation of PFOA $(0.473 \mathrm{ng} / \mathrm{g} \mathrm{dw})$ and the second greatest concentration of PFOS $(0.463 \mathrm{ng} / \mathrm{g} \mathrm{dw})$ were observed at the same site while the greatest PFOS was found at YK3, which is located in the Daliao River adjacent to the city of Yingkou. This was also where the greatest PFOS (30.9 ng/l) was observed in water. This suggested possilbe input from soil to surface waters. In general, soils and sediments in the estuarine and coastal areas of the northern Bohai Sea contain only small amounts of PFCs. In terms of matrix-dependent accumulation of PFCs, the results of the present study were similar to those observed previously in South Korea (Naile et al., 2010).

Mean concentrations of PFOS in water from eight sub-regions were used to calculate field-based bioconcentration factors (BCF) for fish in the estuarine and coastal areas of the northern Bohai Sea. A field-based BCF was defined as the concentration in fish divided by the concentration in water. The mean BCF values for fish were 3,100 with a maximum value of 85,000 at Dalian and a minimum value of 450 at Tangshan with corresponding log BCF values of 2.7-4.9 (Fig. 6). The BCF values found in the present study were comparable to BCF values reported by Taniyasu et al. (log BCF of 2.4-4.6) in Japan (Taniyasu et al., 2003) and Martin et al. (log BCF of 3.0) for their laboratory study of rainbow trout (Martin et al., 2003), but are less than those reported previously in west coastal of Korea ( $\log$ BCF of 3.2-5.1) and in Etobicoke Creek, Ontarion following a spill of AFFF (log BCF of 3.8-5.1) (Moody et al., 2002; Naile et al., 2010). Calculation of log BCF values for PFOA was not possible due to the lack of data for biota. Concentrations of PFOA were less than the limit or quantification in nearly all fish samples. Thus, it can be concluded that PFOA was not bioaccumulated in fish, and this phenomenon was in good agreement with previous studies (Martin et al., 2003; Naile et al., 2010; Quinete et al., 2009; Yeung et al., 2009).

An evaluation of the ecological risk to aquatic animals associated with exposure to PFOS was performed by comparing concentrations in water with water quality values (Giesy et al., 2010; Yoo et al., 2009). Concentrations of PFCs measured in waters around the northern Bohai Sea (all ng/l level) did not approach the numerical water quality criteria (all > several ug/l). Concentrations of PFOS were less than both the criteria maximum concentration $(\mathrm{CMC}=21 \mu \mathrm{g} / \mathrm{l})$ or criteria continuous concentration $(\mathrm{CCC}=$ $5.1 \mu \mathrm{g} / \mathrm{l})$ values, as well as avian wildlife values (AWV $=17 \mathrm{ng} / \mathrm{l})$ (Fig. 6).

While the results of this study indicate little potential for risk, based on concentrations measured in water, risk of environmental exposure to PFCs cannot be neglected because the accumulation mechanisms and exposure routes of PFCs are different than that of more hydrophobic persistent organic pollutants, such as PCBs and dioxins. More toxicological and environmental exposure data are needed to address the effects this class of compounds has on environmental systems (Beach et al., 2006). Also, to make comparisons between concentrations in organisms associated with adverse effects, concentration in the blood, liver and or eggs of birds would be necessary since these are the only values available for which to calculate toxicity reference values (TRVs) (Newsted et al., 2006, 2008; Newsted et al., 2007; Newsted et al., 2005; Yoo et al., 2008).

As part of an ongoing study to determine PFCs concentrations, distributions, sources and environmental fates in the Bohai Sea and Yellow Sea ecosystem, the present study has provided baseline data on PFCs concentrations in water, sediment, soil, and biota col- lected from the estuarine and coastal areas of the northern Bohai Sea. The current findings should help researchers better understand the geographic distributions and extent of PFCs contamination in the estuarine and coastal areas of the Yellow Sea ecoregion including the northern portions of the Bohai Sea. Further detailed work with a more intensive sampling effort with temporal discrimination is recommended to identify any shifts in production to shorter chained or lesser fluorinated PFCs. Such approach will help to elucidate status of trends and source identification, and allow evaluation of control measures to reduce riverine discharge of PFCs into the coastal and marine ecosystem.

\section{Acknowledgements}

This study was supported by the Environmental Protection Welfare Program under Grant No. 201009032, the National Natural Science Foundation of China with Grant No. 41071355, the National Basic Research Program of China ("973" Research Program) with Grant No.2007CB407307 and the National S\&T Support Program under Grant No.2008BAC32B07. Portions of the research were supported by a Discovery Grant from the National Science and Engineering Research Council of Canada (Project No. 326415-07) and a grant from the Western Economic Diversification Canada (Project Nos. 6971 and 6807). Professor Giesy was supported by the Canada Research Chair program and the Visiting Professor Program of King Saud University. This work was also supported, in part, by the National Research Foundation (NRF) grants funded by the Korea government (MEST) (Nos. 2009-0067768 \& 2010-0015275) given to JSK. Finally, we thank the editors and reviewers for their valuable comments and suggestions.

\section{References}

Bao, J., Jin, Y.H., Liu, W., Ran, X.R., Zhang, Z.X., 2009. Perfluorinated compounds in sediments from the Daliao River system of northeast China. Chemosphere 77, 652-657.

Bao, J., Liu, W., Liu, L., Jin, Y.H., Ran, X.R., Zhang, Z.X., 2010. Perfluorinated compounds in urban river sediments from Guangzhou and Shanghai of China. Chemosphere 80, 123-130.

Barber, J.L., Berger, U., Chaemfa, C., Huber, S., Jahnke, A., Temme, C., Jones, K.C., 2007. Analysis of per- and polyfluorinated alkyl substances in air samples from Northwest Europe. J. Environ. Monitor. 9, 530-541.

Beach, S.A., Newsted, J.L., Coady, K., Giesy, J.P., 2006. Ecotoxicological evaluation of perfluorooctanesulfonate (PFOS). Rev. Environ. Contam. Toxicol. 186, 133-174

Becker, A.M., Gerstmann, S., Frank, H., 2008. Perfluorooctanoic acid and perfluorooctane sulfonate in the sediment of the Roter Main river, Bayreuth, Germany. Environ. Pollut. 156, 818-820.

Boulanger, B., Vargo, J., Schnoor, J.L., Hornbuckle, K.C., 2004. Detection of perfluorooctane surfactants in Great Lakes water. Environ. Sci. Technol. 38, 4064-4070.

Chen, C.L., Lu, Y.L., Zhang, X., Geng, J., Wang, T.Y., Shi, Y.J., Hu, W.Y., Li, J., 2009. A review of spatial and temporal assessment of PFOS and PFOA contamination in China. Chem. Ecol. 25, 163-177.

Delinsky, A.D., Strynar, M.J., McCann, P.J., Varns, J.L., McMillan, L., Nakayama, S.F. Lindstrom, A.B., 2010. Geographical distribution of perfluorinated compounds in fish from Minnesota lakes and rivers. Environ. Sci. Technol. 44, 2549-2554.

Dreyer, A., Ebinghaus, R., 2009. Polyfluorinated compounds in ambient air from ship- and land-based measurements in northern Germany. Atmos. Environ.Sci. Technol. 43, 1527-1535.

Fatihah, S., Pramanik, B.K., Shahrom Md, Z., 2009. Contamination, bioaccumulation and toxic effects of perfluorinated chemicals (PFCs) in the water environment: a review paper. Water Sci. Technol. 60, 1533-1544.

Fujii, S., Polprasert, C., Tanaka, S., Lien, N.P.H., Qiu, Y., 2007. New POPs in the water environment: distribution, bioaccumulation and treatment of perfluorinated compounds - a review paper. J. Water Supply Res. T 56, 313-326.

Giesy, J.P., Kannan, K., 2001. Global distribution of perfluorooctane sulfonate in wildlife. Environ. Sci. Technol. 35, 1339-1342.

Giesy, J.P., Kannan, K., 2002. Perfluorochemical surfactants in the environment. Environ. Sci. Technol. 36, 146A-152A.

Giesy, J.P., Naile, J.E., Khim, J.S., Jones, P.D., Newsted, J.L., 2010. Aquatic toxicology of perfluorinated chemicals. Rev. Environ. Contam. Toxicol. 202, 1-52.

Gulkowska, A., Jiang, Q.T., So, M.K., Taniyasu, S., Lam, P.K.S., Yamashita, N., 2006. Persistent perfluorinated acids in seafood collected from two cities of China. Environ. Sci. Technol. 40, 3736-3741. 
Hansen, K.J., Johnson, H.O., Eldridge, J.S., Butenhoff, J.L., Dick, L.A., 2002. Quantitative characterization of trace levels of PFOS and PFOA in the Tennessee River. Environ. Sci. Technol. 36, 1681-1685.

Higgins, C.P., Field, J.A., Criddle, C.S., Luthy, R.G., 2005. Quantitative determination of perfluorochemicals in sediments and domestic sludge. Environ. Sci. Technol. 39, 3946-3956.

Houde, M., Bujas, T.A.D., Small, J., Wells, R.S., Fair, P.A., Bossart, G.D., Solomon, K.R., Muir, D.C.G., 2006. Biomagnification of perfluoroalkyl compounds in the bottlenose dolphin (Tursiops truncatus) food web. Environ. Sci. Technol. 40, 4138-4144.

Hu, W.Y., Wang, T.Y., Khim, J.S., Luo, W., Jiao, W.T., Lu, Y.L., Naile, J.E., Chen, C.L., Zhang, X.A., Giesy, J.P., 2010. HCH and DDT in Sediments from Marine and Adjacent Riverine Areas of North Bohai Sea, China. Arch. Environ. Con. Tox. 59, 71-79.

Jin, Y.H., Ding, M., Di, C., Wang, L., Dong, G.H., Shu, W.Q., Zhang, Y.H., 2006 Monitoring the status of PFOS and PFOA pollution in Sanxia reservoir area of the Yangtze river and surface water of Wuhan. Ecol. Environ. 15, 486-489.

Ju, X.D., Jin, Y.H., Sasaki, K., Saito, N., 2008. Perfluorinated surfactants in surface, subsurface water and microlayer from Dalian Coastal waters in China. Environ. Sci. Technol. 42, 3538-3542.

Kim, S.K., Kannan, K., 2007. Perfluorinated acids in air, rain, snow, surface runoff, and lakes: relative importance of pathways to contamination of urban lakes. Environ. Sci. Technol. 41, 8328-8334.

Kissa, E., 2001. Fluorinated Surfactants and Repellents, second ed. Marcel Decker, New York.

Kwadijk, C.J.A.F., Korytar, P., Koelmans, A.A., 2010. Distribution of perfluorinated compounds in aquatic systems in The Netherlands. Environ. Sci. Technol. 44, 3746-3751.

Lein, N.P.H., Fujii, S., Tanaka, S., Nozoe, M., Tanaka, H., 2008. Contamination of perfluorooctane sulfonate (PFOS) and perfluorooctanoate (PFOA) in surface water of the Yodo River basin (Japan). Desalination 226, 338-347.

Liu, W.X., Chen, J.L., Lin, X.M., Tao, S., 2006. Distribution and characteristics of organic micropollutants in surface sediments from Bohai Sea. Environ. Pollut. $140,4-8$.

Luo, W., Lu, Y., Wang, T., Hu, W., Jiao, W., Naile, J., Khim, J., Giesy, J., 2010. Ecological risk assessment of arsenic and metals in sediments of coastal areas of northern Bohai and Yellow Seas, China. Ambio 39, 367-375.

Mak, Y.L., Taniyasu, S., Yeung, L.W.Y., Lu, G.H., Jin, L., Yang, Y.L., Lam, P.K.S., Kannan, K., Yamashita, N., 2009. Perfluorinated compounds in tap water from China and several other countries. Environ. Sci. Technol. 43, 4824-4829.

Martin, J.W., Mabury, S.A., Solomon, K.R., Muir, D.C., 2003. Bioconcentration and tissue distribution of perfluorinated acids in rainbow trout (Oncorhynchus mykiss). Environ. Toxicol. Chem. 22, 196-204.

Moody, C.A., Martin, J.W., Kwan, W.C., Muir, D.C., Mabury, S.A., 2002. Monitoring perfluorinated surfactants in biota and surface water samples following an accidental release of fire-fighting foam into Etobicoke Creek. Environ. Sci. Technol. 36, 545-551.

Naile, J.E., Khim, J.S., Wang, T.Y., Chen, C.L., Luo, W., Kwon, B.O., Park, J., Koh, C.H., Jones, P.D., Lu, Y.L., Giesy, J.P., 2010. Perfluorinated compounds in water, sediment, soil and biota from estuarine and coastal areas of Korea. Environ. Pollut. 158, 1237-1244.

Nakata, H., Kannan, K., Nasu, T., Cho, H.S., Sinclair, E., Takemura, A., 2006. Perfluorinated contaminants in sediments and aquatic organisms collected from shallow water and tidal flat areas of the Ariake Sea, Japan: environmental fate of perfluorooctanesulfonate in aquatic ecosystems. Environ. Sci. Technol. 40, 4916-4921.

Newsted, J.L., Beach, S.A., Gallagher, S.P., Giesy, J.P., 2006. Pharmacokinetics and acute lethality of perfluorooctanesulfonate (PFOS) to juvenile mallard and northern bobwhite. Arch. Environ. Contam. Toxicol. 50, 411-420.

Newsted, J.L., Beach, S.A., Gallagher, S.P., Giesy, J.P., 2008. Acute and chronic effects of perfluorobutanesulfonate (PFBS) on the mallard and northern bobwhite quail. Arch. Environ. Con. Tox. 54, 535-545.

Newsted, J.L., Coady, K.K., Beach, S.A., Butenhoff, J.L., Gallagher, S., Giesy, J.P., 2007. Effects of perfluorooctane sulfonate on mallard and northern bobwhite quail exposed chronically via the diet. Environ. Toxicol. Phar. 23, 1-9.

Newsted, J.L., Jones, P.D., Coady, K., Giesy, J.P., 2005. Avian toxicity reference values for perfluorooctanesulfonate. Environ. Sci. Technol. 39, 93579362

Pan, Y.Y., Shi, Y.L., Wang, Y.W., Cai, Y.Q., Jiang, G.B., 2010. Investigation of perfluorinated compounds (PFCs) in mollusks from coastal waters in the Bohai Sea of China. J. Environ. Monitor. 12, 508-513.

Quinete, N., Wu, O., Zhang, T., Yun, S.H., Moreira, I., Kannan, K., 2009. Specific profiles of perfluorinated compounds in surface and drinking waters and accumulation in mussels, fish, and dolphins from southeastern Brazil. Chemosphere 77, 863-869.

Rayne, S., Forest, K., 2009. Perfluoroalkyl sulfonic and carboxylic acids: A critical review of physicochemical properties, levels and patterns in waters and wastewaters, and treatment methods. J Environ Sci Heal A 44, 1145-1199.

Rostkowski, P., Yamashita, N., So, I.M.K., Taniyasu, S., Lam, P.K.S., Falandysz, J., Lee, K.T., Kim, S.K., Khim, J.S., Im, S.H., Newsted, J.L., Jones, P.D., Kannan, K., Giesy, J.P. 2006. Perfluorinated compounds in streams of the Shihwa industrial zone and Lake Shihwa, South Korea. Environ. Toxicol. Chem. 25, 2374-2380.

Saito, N., Sasaki, K., Nakatome, K., Harada, K., Yoshinaga, T., Koizumi, A., 2003 Perfluorooctane sulfonate concentrations in surface water in Japan. Arch. Environ. Con. Tox. 45, 149-158.

Sakurai, T., Serizawa, S., Isobe, T., Kobayashi, J., Kodama, K., Kume, G., Lee, J.H., Maki, H., Imaizumi, Y., Suzuki, N., Horiguchi, T., Morita, M., Shiraishi, H., 2010. Spatial, phase, and temporal distributions of Perfluorooctanesulfonate (PFOS) and Perfluorooctanoate (PFOA) in Tokyo Bay, Japan. Environ. Sci. Technol. 44, 41104115.

Senthilkumar, K., Ohi, E., Sajwan, K., Takasuga, T., Kannan, K., 2007. Perfluorinated compounds in river water, river sediment, market fish, and wildlife samples from Japan. B. Environ. Contam. Tox. 79, 427-431.

Shi, Y.L., Pan, Y.Y., Yang, R.Q., Wang, Y.W., Cai, Y.Q., 2010. Occurrence of perfluorinated compounds in fish from Qinghai-Tibetan Plateau. Environ. Int. $36,46-50$.

Sinclair, E., Kannan, K., 2006. Mass loading and fate of perfluoroalkyl surfactants in wastewater treatment plants. Environ. Sci. Technol. 40, 1408-1414.

So, M.K., Miyake, Y., Yeung, W.Y., Ho, Y.M., Taniyasu, S., Rostkowski, P., Yamashita N., Zhou, B.S., Shi, X.J., Wang, J.X., Giesy, J.P., Yu, H., Lam, P.K.S., 2007. Perfluorinated compounds in the Pearl River and Yangtze River of China. Chemosphere 68, 2085-2095.

So, M.K., Taniyasu, S., Lam, P.K.S., Zheng, G.J., Giesy, J.P., Yamashita, N., 2006 Alkaline digestion and solid phase extraction method for perfluorinated compounds in mussels and oysters from south China and Japan. Arch Environ. Con. Tox. 50, 240-248.

So, M.K., Taniyasu, S., Yamashita, N., Giesy, J.P., Zheng, J., Fang, Z., Im, S.H., Lam, P.K.S., 2004. Perfluorinated compounds in coastal waters of Hong Kong, South China, and Korea. Environ. Sci. Technol. 38, 4056-4063.

Taniyasu, S., Kannan, K., Horii, Y., Hanari, N., Yamashita, N., 2003. A survey of Perfluorooctanesulfonate and related perfluorinated organic compounds in water, fish, birds, and humans from Japan. Environ. Sci. Technol. 37, 2634-2639.

Wang, T. Wang, Y.W. Liao, C.Y. Cai, Y.Q. Jiang, G.B., 2009. Perspectives on the inclusion of Perfluorooctanesulfonate into the stockholm convention on persistent organic pollutants. Environ. Sci. Technol. 43, 5171-5175.

Wang, T.Y., Yonglong, L., Hong, Z., Yajuan, S., 2005. Contamination of persistent organic pollutants (POPs) and relevant management in China. Environ. Int. 31, 813-821.

Yamashita, N., Kannan, K., Taniyasu, S., Horii, Y., Okazawa, T., Petrick, G., Gamo, T., 2004. Analysis of perfluorinated acids at parts-per-quadrillion levels in seawater using liquid chromatography-tandem mass spectrometry. Environ. Sci. Technol. 38, 5522-5528.

Yamashita, N., Kannan, K., Taniyasu, S., Horii, Y., Petrick, G., Gamo, T., 2005. A global survey of perfluorinated acids in oceans. Mar. Pollut. Bull. 51, 658-668.

Yeung, L.W., Yamashita, N., Taniyasu, S., Lam, P.K., Sinha, R.K., Borole, D.V., Kannan, K., 2009. A survey of perfluorinated compounds in surface water and biota including dolphins from the Ganges River and in other water bodies in India. Chemosphere 76, 55-62.

Yoo, H., Kannan, K., Kim, S.K., Lee, K.T., Newsted, J.L., Giesy, J.P., 2008. Perfluoroalkyl acids in the egg yolk of birds from Lake Shihwa, Korea. Environ. Sci. Technol. 42, 5821-5827.

Yoo, H., Yamashita, N., Taniyasu, S., Lee, K.T., Jones, P.D., Newsted, J.L., Khim, J.S., Giesy, J.P., 2009. Perfluoroalkyl acids in marine organisms from Lake Shihwa, Korea. Arch. Environ. Con. Tox. 57, 552-560.

Zhang, P., Song, J.M., Yuan, H.M., 2009. Persistent organic pollutant residues in the sediments and mollusks from the Bohai Sea coastal areas, North China: an overview. Environ. Int. 35, 632-646.

Zhang, T., Wu, Q., Sun, H.W., Zhang, X.Z., Yun, S.H., Kannan, K., 2010. Perfluorinated compounds in whole blood samples from infants, children, and adults in China. Environ. Sci. Technol. 44, 4341-4347.

Zhang, Z.H., Zhu, M.Y., Wang, Z.L., Wang, J., 2006. Monitoring and managing pollution load in Bohai Sea, PR China. Ocean Coast. Manage. 49, 706-716.

Zhao, X., Li, J., Shi, Y., Cai, Y., Mou, S., Jiang, G., 2007. Determination of perfluorinated compounds in wastewater and river water samples by mixed hemimicellebased solid-phase extraction before liquid chromatography-electrospray tandem mass spectrometry detection. J. Chromatogr. A 1154, 52-59. 